\title{
Modeling radiative transfer in tropical rainforest canopies: sensitivity of simulated albedo to canopy architectural and optical parameters
}

\author{
SÍLVIA N.M. YANAGI ${ }^{1}$ and MARCOS H. COSTA $^{2}$ \\ ${ }^{1}$ Departamento de Engenharia, Universidade Federal de Lavras, \\ Caixa Postal 3037, 37200-000 Lavras, MG, Brasil \\ ${ }^{2}$ Departamento de Engenharia Agrícola, Universidade Federal de Viçosa, \\ Av. P.H. Rolfs, s/n, 36570-000 Viçosa, MG, Brasil \\ Manuscript received on October 22, 2009; accepted for publication on May 11, 2011
}

\begin{abstract}
This study evaluates the sensitivity of the surface albedo simulated by the Integrated Biosphere Simulator (IBIS) to a set of Amazonian tropical rainforest canopy architectural and optical parameters. The parameters tested in this study are the orientation and reflectance of the leaves of upper and lower canopies in the visible (VIS) and near-infrared (NIR) spectral bands. The results are evaluated against albedo measurements taken above the K34 site at the INPA (Instituto Nacional de Pesquisas da Amazônia) Cuieiras Biological Reserve. The sensitivity analysis indicates a strong response to the upper canopy leaves orientation $\left(\chi_{u p}\right)$ and to the reflectivity in the near-infrared spectral band $\left(\rho_{N I R, u p}\right)$, a smaller sensitivity to the reflectivity in the visible spectral band $\left(\rho_{V I S, u p}\right)$ and no sensitivity at all to the lower canopy parameters, which is consistent with the canopy structure. The combination of parameters that minimized the Root Mean Square Error and mean relative error are $\chi_{u p}=0.86, \rho_{V I S, u p}=0.062$ and $\rho_{N I R, u p}=0.275$. The parameterizations performed resulted in successful simulations of tropical rainforest albedo by IBIS, indicating its potential to simulate the canopy radiative transfer for narrow spectral bands and permitting close comparison with remote sensing products.
\end{abstract}

Key words: Amazonian Tropical Forest, albedo, radiative transfer, modeling.

\section{INTRODUCTION}

Global climate models (GCMs) simulate the evolution of the climate based on physical principles as well as on initial and boundary conditions. To do so, these models must represent the exchanges of radiation, heat, momentum and mass between the atmosphere and the underlying surface, in particular in terrestrial environments. Practical considerations, however, require that small scale processes be parameterized in terms of larger scale variables.

Correspondence to: Sílvia Nazaré Monteiro Yanagi

E-mail: snmonteiro@yahoo.com.br 
The parameterization of terrestrial surface processes in climate models is confined to modules implementing vertical exchange models. The radiation component of these modules relies on solutions derived from two-stream approaches (Dickinson 1983, Sellers 1985), which follow developments made in the field of atmospheric physics (Coakley and Chylek 1975, Meador and Weaver 1980). Compared to the atmosphere analogue, the radiation transfer in plant canopies is rendered complex because the elementary scatterers - leaves and stems - are large compared to the typical wavelength of solar radiation, can be oriented and clumped and they exhibit complex variable optical properties (Pinty et al. 2006). The twostream formulations thus have to be adapted to represent, at least in simplified forms, the effects of these complexities. Solutions have been developed for multiple possibilities of leaves and stems orientations, from strictly vertical (eroctophile) to strictly horizontal (planophile), including spherical (equal probability for all leaf orientations) and any other orientation in between, allowing a more realistic representation of vegetation canopies (Pinty et al. 2006).

GCM-grade radiation transfer schemes are constrained by several limitations: they must be computer efficient and numerically stable, use measurable or retrievable variables or parameters, provide sufficiently accurate estimations of the radiant fluxes, and respect energy conservation principles, which require that reflected, transmitted and absorbed fluxes sum up to the incident radiation, independent of the assumed canopy structure inside the domain. Radiation schemes should, therefore, be able to simulate accurately both the flux reflected from the top of the canopy, that is its albedo, and the flux transmitted to the ground underneath the vegetation layer. In this modeling context, the albedo is a prime candidate for validation exercises.

Here in this study we use the above canopy albedo as the main indicator of model performance, and evaluate the sensitivity of the simulated albedo of a tropical rainforest to a set of canopy architectural and optical parameters, with the goals of (a) understanding the response of the model to the several canopy optical parameters, and (b) obtaining the best set of parameters to be used in climate models, in particular leaves and stems orientation. We model the radiative transfer using the radiative transfer module of the Integrated Biosphere Simulator (IBIS) and validate the simulations against albedo measurements taken at the tropical rainforest site at the Cuieiras Biological Reserve (K34).

\section{METHODS}

\section{IBIS DESCRIPTION}

In this study, a 0-D version of the Integrated Biosphere Simulator-IBIS (Foley et al. 1996) is used to model the radiative transfer in a tropical rainforest canopy. Although the model includes representations of several land surface processes (energy, water and momentum exchange among the soil-vegetation-atmosphere system, canopy physiology, vegetation phenology, vegetation dynamics and terrestrial carbon balance), this study concerns only the solar radiation balance.

The albedo of a vegetation canopy layer $(\alpha)$ is defined as the ratio of the upwelling to the downwelling solar radiant fluxes at the top of the canopy, both depending on the location of the source, i.e., the cosine of the Sun zenith angle $(\mu)$ and type of illumination (normally both direct and diffuse). Representing of the albedo of such system requires the adoption of assumptions or simplifications. IBIS assumes that the 
surface albedo is approximated by a simple weighting of two distinct surface albedo types, each associated with an incident irradiance field: the directional hemispherical reflectance $\left(\alpha^{d}\right)$, associated with an incident irradiance field that is purely collimated $\left(I_{i n}^{d}\right)$, and the indirect hemispherical reflectance $\left(\alpha^{i}\right)$, associated with an incident irradiance field that is purely isotropic $\left(I_{i n}^{i}\right)$. Both albedo types can be combined to approximate the surface albedo as follows (Kondratyev 1972):

$$
\alpha=\frac{I_{i n}^{d} \alpha^{d}+I_{i n}^{i} \alpha^{i}}{I_{i n}^{d}+I_{i n}^{i}}
$$

In IBIS, the exchange of solar radiation among the soil-vegetation-atmosphere system is calculated following the standard two-stream approximation, with separate calculations for direct and diffuse radiation in both visible and near-infrared bands. It solves the canonical radiative transfer problem of two-stream vegetation layer plus underlying surface of known albedo. Starting from the known soil albedo $\left(\alpha_{g}\right)$, the method first calculates the albedo of the combined lower canopy-ground system $\left(\alpha_{g-l o}\right)$, then the albedo of the combined upper canopy-lower canopy-soil system $\left(\alpha_{l o-u p}\right)$.

As shown in Figure 1, effects of clumping and partial vegetation cover are also treated. When fluxes are passed between the upper and lower story, or between the lower story and the ground, the two-stream fluxes passing through the canopy are merged with the unmodified fluxes passing through the gaps (weighting with respect to the appropriate fractional cover $f_{u p}$ or $f_{l o}$ ). Assuming that there is no snow in the canopy, the albedo of each spectral band $\Lambda$ is given by:

$$
\begin{gathered}
\alpha_{g-l o \Lambda}^{d}=\alpha_{g \Lambda}^{d} \cdot\left(1-f_{l o}\right)+\alpha_{l o \Lambda}^{d} f_{l o} \\
\alpha_{g-l o \Lambda}^{i}=\alpha_{g \Lambda}^{i} \cdot\left(1-f_{l o}\right)+\alpha_{l o \Lambda}^{i} f_{l o} \\
\alpha_{l o-u p \Lambda}^{d}=\alpha_{g-l o \Lambda}^{d} \cdot\left(1-f_{u p}\right)+\alpha_{u p \Lambda}^{d} f_{u p} \\
\alpha_{l o-u p \Lambda}^{i}=\alpha_{g-l o \Lambda}^{i} \cdot\left(1-f_{u p}\right)+\alpha_{u p \Lambda}^{i} f_{u p}
\end{gathered}
$$

The two-stream algorithm uses several canopy architectural and optical parameters. The canopy architectural parameters include the upper and lower canopy element orientation $\left(\chi_{u p}\right.$ and $\left.\chi_{l o}\right)$, the fraction of ground area covered by lower and upper canopy $\left(f_{l o}\right.$ and $\left.f_{u p}\right)$, the leaf area and stem area indexes ( $\mathrm{L}$ and $\mathrm{S}$, respectively). The canopy optical parameters include the upper and lower canopy leaf reflectance by visible (VIS) and near-infrared (NIR) spectral band $\Lambda\left(\rho_{\Lambda}: \rho_{V I S, u p}, \rho_{V I S, l o}, \rho_{N I R, u p}\right.$ and $\left.\rho_{N I R, l o}\right)$, and the upper and lower canopy leaf transmittance by visible (VIS) and near-infrared (NIR) spectral band $\Lambda\left(\tau_{\Lambda}\right.$ : $\tau_{V I S, \text { up }}, \tau_{V I S, l o}, \tau_{\text {NIR,up }}$ and $\left.\tau_{\text {NIR,lo }}\right)$. The procedure below describes the major theoretical aspects of the twostream approximation, and must be repeated for each vegetation layer.

Within each vegetation layer, the upward and downward diffuse fluxes obey

$$
\begin{aligned}
& -\bar{\mu} \frac{d I^{\uparrow}}{d(L+S)}+\left[1-\left(1-\beta^{i}\right) \omega\right] I^{\uparrow}-\omega \beta^{i} I_{\downarrow}=\omega \bar{\mu} K \beta^{d} e^{-K(L+S)} \\
& -\bar{\mu} \frac{d I_{\downarrow}}{d(L+S)}+\left[1-\left(1-\beta^{i}\right) \omega\right] I^{\downarrow}-\omega \beta^{i} I^{\uparrow}=\omega \bar{\mu} K\left(1-\beta^{d}\right) \cdot e^{-K(L+S)},
\end{aligned}
$$


where $I^{\uparrow}$ and $I^{\downarrow}$ are the upward and downward diffuse radiative fluxes per unit incident flux, $K=G(\mu) / \mu$ is the optical depth of direct beam per unit leaf and stem area, $G(\mu)$ is the relative projected area of leaf and stem elements in the direction $\cos ^{-1} \mu, \bar{\mu}$ is the average inverse diffuse optical depth per unit leaf and stem area, $\omega$ is a scattering coefficient, $\beta^{i}$ and $\beta^{d}$ are upscatter parameters for indirect (diffuse) and direct beam radiation, respectively, $L$ is the single-sided leaf area index, and $S$ is the single-sided stem area index. Given the direct beam ground albedo $\alpha_{g, \Lambda}^{d}$ and diffuse ground albedo $\alpha_{g, \Lambda}^{i}$ for each spectral band $\Lambda$, these equations are solved to calculate the fluxes, per unit incident flux, absorbed by the vegetation, reflected by the vegetation, and transmitted through the vegetation for direct and diffuse radiation, for visible $(\Lambda<0.7 \mu \mathrm{m})$ and near-infrared $(\Lambda \geq 0.7 \mu \mathrm{m})$ spectral bands.

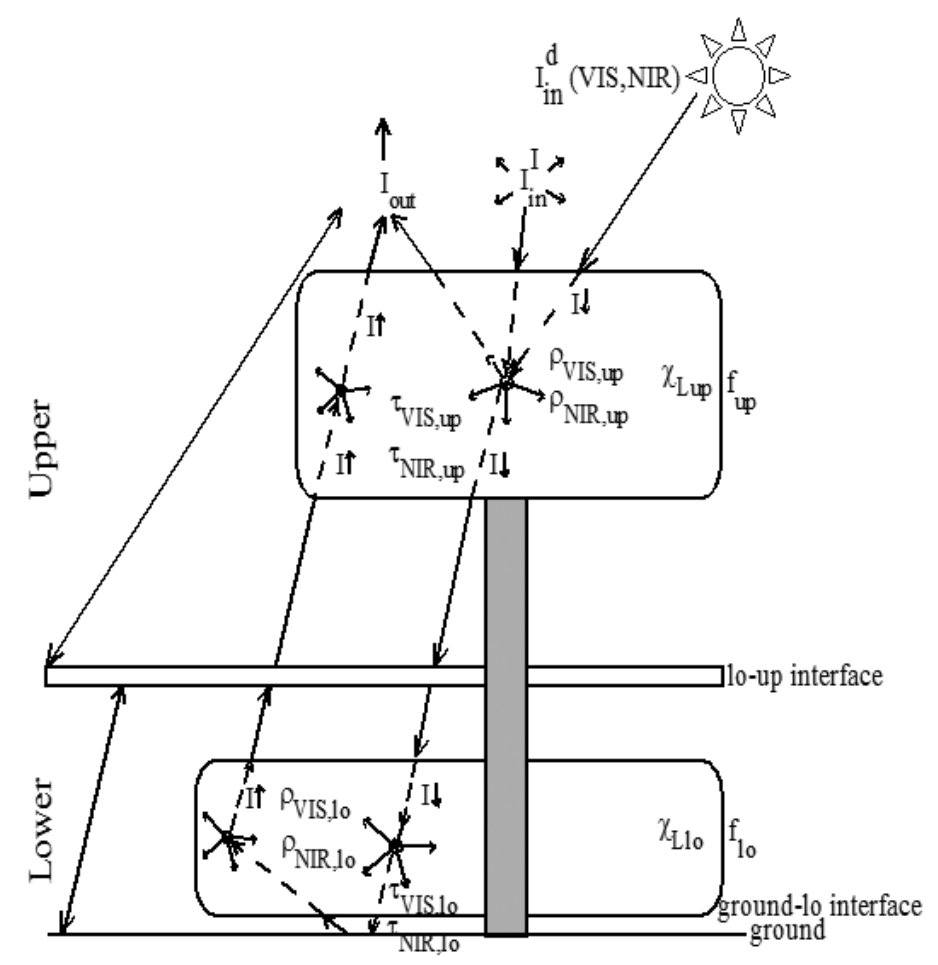

Fig. 1 - Schematic representation of the radiative transfer model in IBIS.

Equations (6) and (7) are then solved analytically for a two-stream layer underlain by a non-specular surface of known albedo (i.e., the ground), with prescribed incoming downward direct and diffuse fluxes. This canonical solution (Eqs. 15 and 16) is applied first to the lower story underlain by soil to obtain the effective albedo of that system, then to the upper story underlain by the lower story and soil system, yielding the overall canopy albedo. The analytical solutions for the single scattering albedo of direct $\left(\alpha_{\Lambda}^{d}\right)$ and indirect $\left(\alpha_{\Lambda}^{i}\right)$ fluxes are

$$
\begin{aligned}
\alpha_{\Lambda}^{d}= & \frac{h_{1}}{\sigma}+\frac{1}{d_{1} e^{-h(L+S)}}\left\{\left[\omega_{\Lambda} \bar{\mu} K \beta_{\Lambda}^{d}-\frac{h_{1}}{\sigma}(b+\bar{\mu} K)\right] \cdot\left[\left(b-\bar{\mu} h-\frac{\omega_{\Lambda} \beta_{\Lambda}^{i}}{\alpha_{g \Lambda}^{d}}\right)-b+\bar{\mu} h\right]\right\} \\
& -\frac{1}{d_{1}}\left\{\left[\omega_{\Lambda} \bar{\mu} K \beta_{\Lambda}^{d}-\frac{h_{1}}{\sigma}(b+\bar{\mu} K)\right] \cdot\left[\left(b+\bar{\mu} h-\frac{\omega_{\Lambda} \beta_{\Lambda}^{i}}{\alpha_{g \Lambda}^{d}}\right) \cdot e^{-h(L+S)}\right]-\frac{b+\bar{\mu} h}{e^{-h(L+S)}}\right\}
\end{aligned}
$$




$$
\begin{aligned}
\alpha_{\Lambda}^{i}= & \omega_{\Lambda} \beta_{\Lambda}^{i}\left\{(b+\bar{\mu} h)-\left[(b-\bar{\mu} h) \cdot\left(\frac{b+\bar{\mu} h-\frac{\omega_{\Lambda} \beta_{\Lambda}^{i}}{\alpha_{g \Lambda}^{i}}}{b-\bar{\mu} h-\frac{\omega_{\Lambda} \beta_{\Lambda}^{i}}{\alpha_{g \Lambda}^{i}}}\right) \cdot\left[e^{-h(L+S)}\right]^{2}\right]\right. \\
& \left.-\left[\frac{(b+\bar{\mu} h)}{\left[e^{-h(L+S)}\right]^{2}} \cdot\left(\frac{b-\bar{\mu} h-\frac{\omega_{\Lambda} \beta_{\Lambda}^{i}}{\alpha_{g \Lambda}^{i}}}{b+\bar{\mu} h-\frac{\omega_{\Lambda} \beta_{\Lambda}^{i}}{\alpha_{g \Lambda}^{i}}}\right)-b+\bar{\mu} h\right]\right\}^{-1},
\end{aligned}
$$

where:

$$
\begin{aligned}
& b=1-\omega_{\Lambda}\left(1-\beta_{\Lambda}^{i}\right), \\
& \frac{h_{1}}{\sigma}=\frac{-\omega_{\Lambda} \bar{\mu} K\left[\beta_{\Lambda}^{d}(b-\bar{\mu} K)+\omega_{\Lambda} \beta_{\Lambda}^{i}\left(1-\beta_{\Lambda}^{d}\right)\right]}{(\bar{\mu} K)^{2}-\left[b^{2}-\left(\omega_{\Lambda} \beta_{\Lambda}^{i}\right)^{2}\right]}, \\
& h=\frac{\sqrt{b^{2}-\left(\omega_{\Lambda} \beta_{\Lambda}^{i}\right)^{2}}}{\bar{\mu}} \text { and } \\
& d_{1}=\left[\frac{(b+\bar{\mu} h)}{\left.e^{-h(L+S)} \cdot\left(b-\bar{\mu} h-\frac{\omega_{\Lambda} \beta_{\Lambda}^{i}}{\alpha_{g \Lambda}^{d}}\right)\right]-\left[(b-\bar{\mu} h) \cdot\left(b+\bar{\mu} h-\frac{\omega_{\Lambda} \beta_{\Lambda}^{i}}{\alpha_{g \Lambda}^{d}}\right) \cdot e^{-h(L+S)}\right] .}\right.
\end{aligned}
$$

The remaining issue to be described concerns the relevant expressions for $G(\mu), \omega, \beta^{i}, \beta^{d}$, and $\bar{\mu}$. In the specific case of structurally homogeneous vegetation canopy layers, the elementary scatterers are modeled as oriented plates of finite small size. Depending on the vegetation type and environmental conditions, the orientation probability of the normals to these plates may follow various distributions including planophile, erectophile, or even heliotropic. Once the function of the distribution of leaf angle probability is given, it becomes feasible to express the extinction coefficient of any elementary volume and, thus, the total extinction of the vertically homogeneous vegetation layer (e.g., Ross 1981, Dickinson 1983, Verstraete 1987). This extinction coefficient, traditionally expressed with Ross (1981) $G$ function, modulates the optical thickness of the homogeneous vegetation layer. The generic expression for leaves with an orientation parameter $\chi$ is

$$
G(\mu)=\frac{1}{2}+\left(\frac{4 \sqrt{1-\mu^{2}}-\pi}{2 \pi}\right) \chi^{v}+\left(\frac{2 \mu-1}{2}\right) \chi^{h},
$$

where the leaf orientation $\chi$, also defined as the departure of leaf angles from a random distribution, equals +1 for horizontal leaves, 0 for random leaves, and -1 for vertical leaves. $\chi^{h}$ and $\chi^{v}$ are the positive and negative parts of $\chi$, respectively.

The $\omega \beta^{i}$ and $\omega \beta^{d}$ parameters should thus be expressed via the $G$ function and the distribution of leaf orientation probability. The $\omega \beta$ parameter is the integral over the appropriate distribution of leaf orientation probability, performed between 0 and $\pi / 2$, of the scatter parameter of an individual scattering element, leaf or stem (Norman and Jarvis 1975). Solving the integral, the upscatter parameter for diffuse radiation is

$$
\omega_{\Lambda} \beta_{\Lambda}^{i}=\chi^{v}\left(\frac{\rho_{\Lambda}+\tau_{\Lambda}}{6}\right)+\chi^{h}\left(\frac{\rho_{\Lambda}-\tau_{\Lambda}}{3}\right)+\left(\frac{2 \rho_{\Lambda}+\tau_{\Lambda}}{3}\right)
$$


and the upscatter parameter for direct beam radiation is

$$
\omega_{\Lambda} \beta_{\Lambda}^{d}=\chi^{v} \frac{2 c(\mu)-1}{2}\left(\rho_{\Lambda}-\tau_{\Lambda}\right)+\chi^{h} c(\mu) \cdot\left(\rho_{\Lambda}-\tau_{\Lambda}\right)+\rho_{\Lambda}[1-c(\mu)]+\tau_{\Lambda} c(\mu),
$$

where $c(\mu)$ is a transmittance coefficient that varies between 0.5 for $\mu=0$ and 0.1667 for $\mu=1$.

By definition, the scattering coefficient is the sum of the reflectance and transmittance of the scattering element:

$$
\omega_{\Lambda}=\rho_{\Lambda}+\tau_{\Lambda},
$$

where $\rho_{\Lambda}$ is a weighted combination of the leaf and stem reflectances $\left(\rho_{\Lambda}^{\text {leaf }}, \rho_{\Lambda}^{\text {stem }}\right)$ :

$$
\rho_{\Lambda}=\rho_{\Lambda}^{\text {leaf }} w_{\text {leaf }}+\rho_{\Lambda}^{\text {stem }} w_{\text {stem }}
$$

where $w_{\text {leaf }}=L /(L+S)$ and $w_{\text {stem }}=S /(L+S) ; \tau_{\Lambda}$ is a weighted combination of the leaf and stem transmittances $\left(\tau_{\Lambda}^{\text {leaf }}, \tau_{\Lambda}^{\text {stem }}\right)$

$$
\tau_{\Lambda}=\tau_{\Lambda}^{\text {leaf }} w_{\text {leaf }}+\tau_{\Lambda}^{\text {stem }} w_{\text {stem }} .
$$

Finally, the average inverse diffuse optical depth per unit leaf and stem area $(\bar{\mu})$ is given by

$$
\bar{\mu}=\int_{0}^{1} \frac{\mu^{\prime}}{G\left(\mu^{\prime}\right)} d \mu^{\prime}
$$

after Dickinson (1983). $\bar{\mu}$ varies between 0.90 and 1.04 for the planophile and erectophile cases, and 1.00 for the spherical cases.

\section{EXPERIMENTAL SITE AND DATA}

Field data used in this study were measured at the K34 site in the Cuieiras Biological Reserve $\left(2^{\circ} 35^{\prime} \mathrm{S}\right.$, $60^{\circ} 07^{\prime} \mathrm{W}, 90 \mathrm{~m}$ above sea level) during the LBA project (Large-Scale Biosphere-Atmosphere Experiment in Amazônia). The Cuieiras Biological Reserve is an INPA (Instituto Nacional de Pesquisas da Amazônia) protected forest reserve about $60 \mathrm{~km}$ north of Manaus, which is embedded in a vast area of pristine rainforest. The $50 \mathrm{~m}$ tall $\mathrm{K} 34$ tower, erected in 1999 , is located on a medium-sized plateau $\left(2^{\circ} 36^{\prime} 32.67^{\prime \prime} \mathrm{S}\right.$, $60^{\circ} 12^{\prime} 33.48^{\prime \prime} \mathrm{W}, 130 \mathrm{~m}$ ) (Araújo et al. 2002). The natural vegetation and topography of this site are representative of much of central Amazônia.

For the albedo determination, we used hourly incident and reflected solar radiation data collected from June 1999 to September 2000 by a piranometer (Kipp \& Zonen CM 21, Delft, Netherlands) installed at $44.6 \mathrm{~m}$ height above the forest ground surface and connected to a datalogger (CR10, Campbell Scientific, Shepshed, UK). The data were measured at every 30 seconds, and the averages stored at every 30 minutes.

\section{Sensitivity to CANopy Architectural and OpticAl Parameters}

We carried out a sensitivity analysis of the albedo simulated by the model to six canopy architectural and optical parameters: the upper canopy leaf and stem orientation $\left(\chi_{u p}\right)$, the lower canopy leaf orientation $\left(\chi_{l o}\right)$, upper and lower canopy leaf reflectance on visible (VIS) and near-infrared (NIR) spectral band 
TABLE I

Parameters used by the model.

\begin{tabular}{lc}
\hline Architectural parameters & Value \\
\hline single-sided leaf area index $(L)$ & 6.175 \\
single-sided stem area index $(S)$ & 0.025 \\
fraction of overall area covered by lower canopy $\left(f_{l o}\right)$ & 0.500 \\
fraction of overall area covered by upper canopy $\left(f_{u p}\right)$ & 0.975 \\
\hline \hline Optical parameters & 0.10 \\
\hline direct and diffuse beam ground albedo on visible (VIS) spectral band $\left(a_{g, V I S}\right)$ & 0.40 \\
direct and diffuse beam ground albedo on near-infrared (NIR) spectral band $\left(a_{g, N I R}\right)$ & 0.07 \\
lower canopy leaf transmittance on visible (VIS) spectral band $\left(\tau_{V I S, l o}\right)$ & 0.05 \\
upper canopy leaf transmittance on visible (VIS) spectral band $\left(\tau_{V I S, u p}\right)$ & 0.25 \\
lower canopy leaf transmittance on near-infrared (NIR) spectral band $\left(\tau_{N I R, l o}\right)$ & 0.20 \\
upper canopy leaf transmittance on near-infrared (NIR) spectral band $\left(\tau_{N I R, u p}\right)$ & \\
\hline
\end{tabular}

$\Lambda\left(\rho_{\Lambda}: \rho_{V I S, u p}, \rho_{V I S, l o}, \rho_{N I R, u p}\right.$ and $\rho_{N I R, l o}$, respectively). Other canopy architectural and optical parameters are set to the values in Table I. The model is then run several times with different combinations of the parameters above, to determine in detail the sensitivity of the model to these parameters.

The sensitivity analysis was based on statistical methods, such as mean relative error $(\varepsilon)$ and Root Mean Square Error (RMSE) that are defined according to Equations 17 and 18:

$$
\begin{gathered}
\varepsilon=\frac{1}{n} \sum_{i=1}^{n} \frac{\left(X_{i}^{s}-X_{i}^{o}\right)}{X_{i}^{o}} \\
R M S E=\sqrt{\frac{\sum_{i=1}^{n}\left(X_{i}^{s}-X_{i}^{o}\right)^{2}}{n},}
\end{gathered}
$$

where $X^{s}$ and $X^{o}$ are the simulated and observed albedos, and $n$ is the number of data points.

\section{RESULTS AND DISCUSSION}

Several sensitivity tests for $\chi_{l o}, \rho_{V I S, u p}, \rho_{V I S, l o}$ and $\rho_{N I R, l o}$ have shown that the values of RMSE and mean error of the simulated and observed albedos were not sensitive to the variation of these parameters. Thus, we adopted fixed values of $\chi_{l o}=0.1, \rho_{V I S, l o}=0.062, \rho_{V I S, u p}=0.062$ and $\rho_{N I R, l o}=0.60$ (Figs. 2 and 3), being $\rho_{V I S, l o}$ and $\rho_{V I S, u p}$ equal to the default of the studied model. Then, the values of $\chi_{u p}$ and $\rho_{N I R, u p}$ were determined which resulted in smallest values of RMSE and mean error.

RMSE and mean error analyses indicate that the model is not sensitive to the parameters previously cited, and it is consistent with an ecosystem of tropical rainforest because the parameter $\chi_{l o}$ that controls the leaf orientation, as well as $\rho_{V I S, l o}$ and $\rho_{N I R, l o}$ that control the lower canopy reflectance in the visible and infrared wavebands, receive little solar radiation. This is due to the upper canopy being very dense and, thus, avoiding the entrance of a larger amount of solar radiation and not influencing the albedo too much. For visible radiation, this limit gives about $90 \%$ of the scattered radiation from a vegetated surface because of the strong absorption by chlorophyll (Dickinson et al. 1990). 

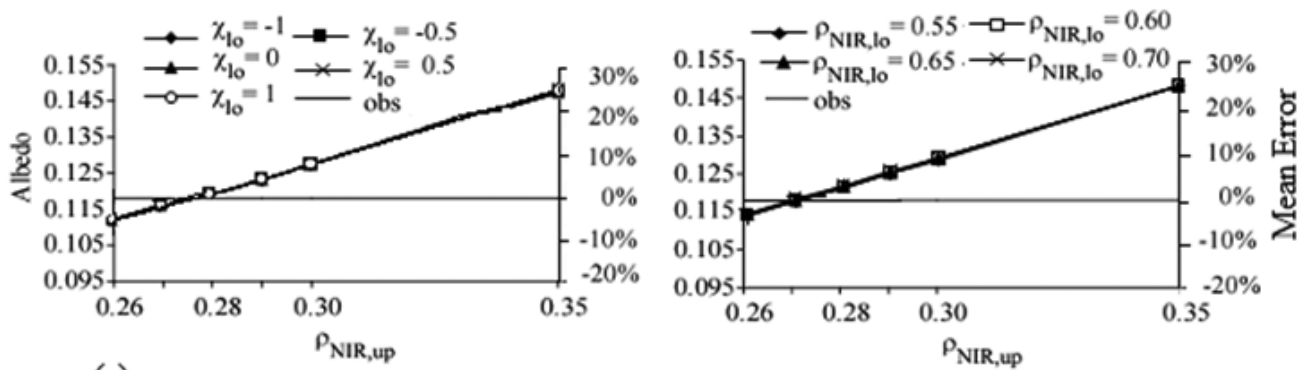

(a) $\chi_{\text {up }}=0.86 \rho_{\mathrm{viS}, \text { up }}$ and $\rho_{\mathrm{viS}, \mathrm{lo}}=0.062$ $\rho_{\mathrm{NIR}, \mathrm{lo}}=0.60$

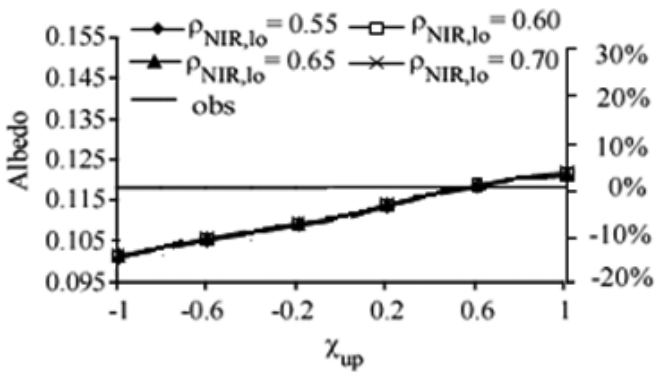

(b) $\chi_{\text {up }}=0.86 \chi_{\text {lo }}=0.1 \rho_{\text {VIS,up }}$ and $\rho_{\mathrm{VIS}, \mathrm{lo}}=0.062$

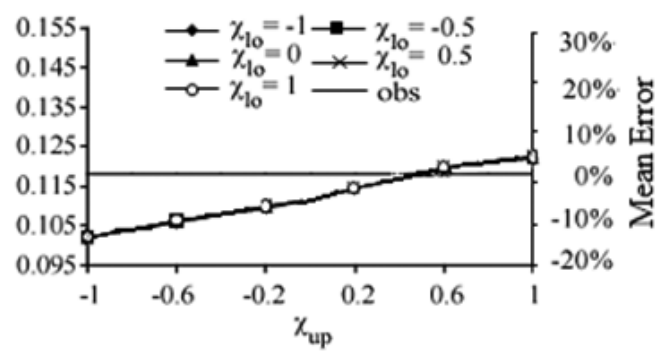

(c) $\chi_{1 \mathrm{o}}=0.1 \rho_{\mathrm{VIS}, \text { up }}$ and $\rho_{\mathrm{VIS}, \mathrm{lo}}=0.062$
$\rho_{\mathrm{NIR}, \text { up }}=0.28$

(d) $\rho_{\mathrm{VIS} \text {,up }}$ and $\rho_{\mathrm{VIS}, \mathrm{lo}}=0.062 \rho_{\mathrm{NIR}, \mathrm{lo}}=0.60$ $\rho_{\mathrm{NIR}, \text { up }}=0.28$

Fig. 2 - Sensitivity analysis of the simulated albedo and its mean error as a function of a) $\rho_{N I R, u p}$ and $\chi_{l o}$, b) $\rho_{N I R, u p}$ and $\rho_{N I R, l o}$, c) $\chi_{u p}$ and $\rho_{N I R, l o}$, and d) $\chi_{u p}$ and $\chi_{l o}$, for the Cuieiras Biological Reserve (K34).
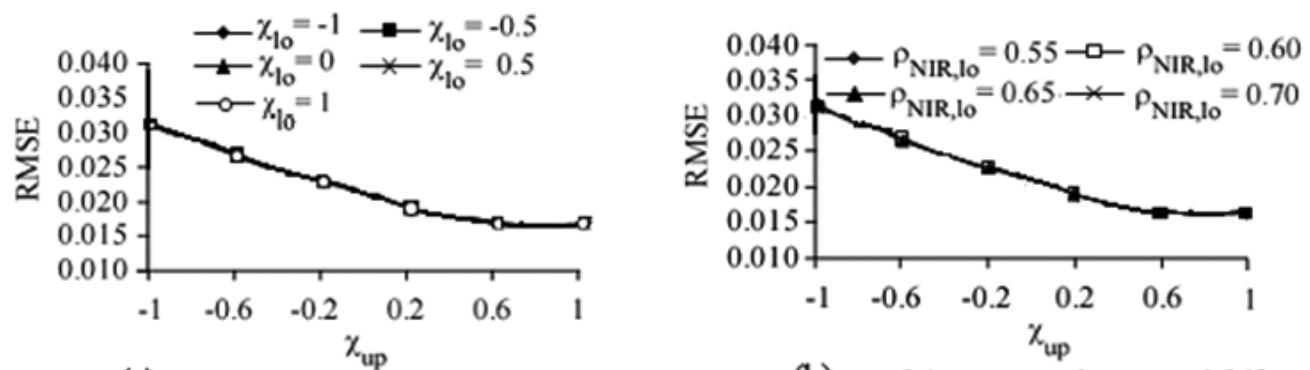

$\begin{aligned} & \text { (a) } \rho_{\text {VIS,up }} \text { and } \rho_{\text {VIS,lo }} \chi_{\text {up }} \\ & \rho_{\text {NIR,up }} \\ & =0.28\end{aligned}=0.062 \rho_{\text {NIR,lo }}=0.60$

(b) $\chi_{\mathrm{lo}_{\mathrm{o}}}=0.1 \rho_{\mathrm{VIS}, \mathrm{up}}$ and $\rho_{\mathrm{VIS}, \mathrm{lo}}=0.062$ $\rho_{\mathrm{NIR}, \text { up }}=0.28$

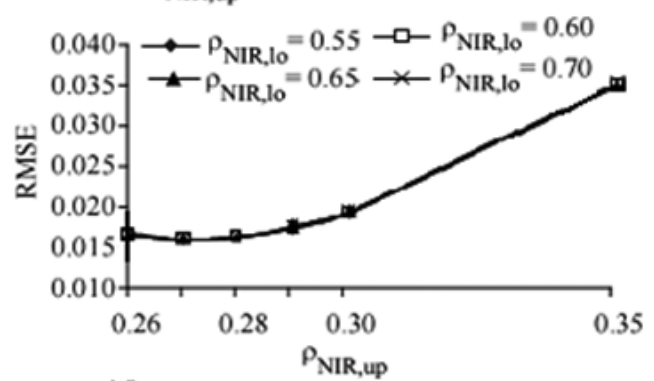

(c) $\chi_{\text {up }}=0.86 \rho_{\mathrm{VIS}, \text { up }}$ and $\rho_{\mathrm{YIS}, \mathrm{lo}}=0.062$ $\rho_{\text {NIR,lo }}=0.60$ (d) $\chi_{\text {up }}=0.86 \chi_{\mathrm{lo}}=0.1 \rho_{\mathrm{VIS}, \text { up }}$ and $\rho_{\text {VIS, } 10}=0.062$

Fig. 3 - Root Mean Square Error (RMSE) as a function of a) $\chi_{u p}$ and $\chi_{l o}$, b) $\chi_{u p}$ and $\rho_{N I R, l o}$, c) $\rho_{N I R, u p}$ and $\chi_{l o}$, and d) $\rho_{N I R, u p}$ and $\rho_{N I R, l o}$, for the Cuieiras Biological Reserve (K34). 
Several combinations of $\chi_{u p}, \rho_{V I S, u p}$ and $\rho_{N I R, u p}$ are tested to search for the best mean simulated value of surface albedo for the period in study. A strong sensitivity of the simulated albedo to these parameters is observed, resulting in optimal values of simulated albedo for $\rho_{V I S}$ between 0.05 and 0.07 , for $\rho_{N I R, u p}$ between 0.27 and 0.28 , and for $\chi_{u p}$ between 0.6 and 0.9 (Fig. 4). This range of $\chi_{u p}$ characterizes a predominance of upper canopy elements (leaves and stems) with low inclination angle with respect to the horizontal.

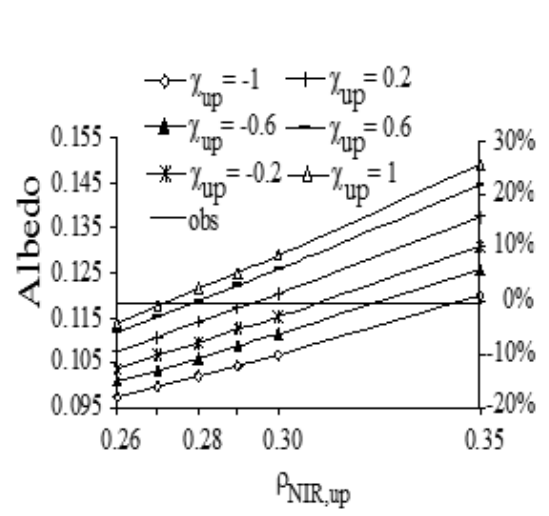

(a)

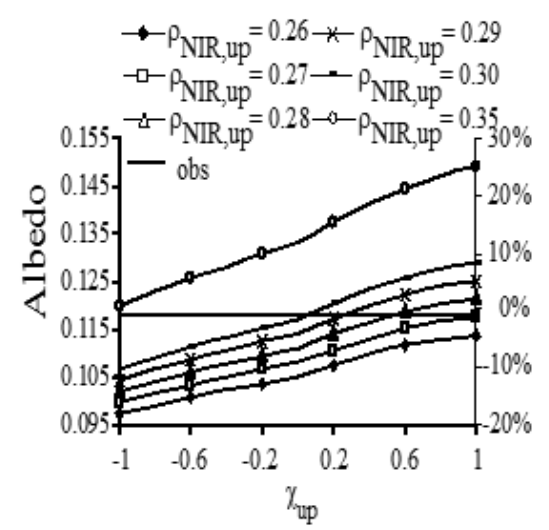

(c)

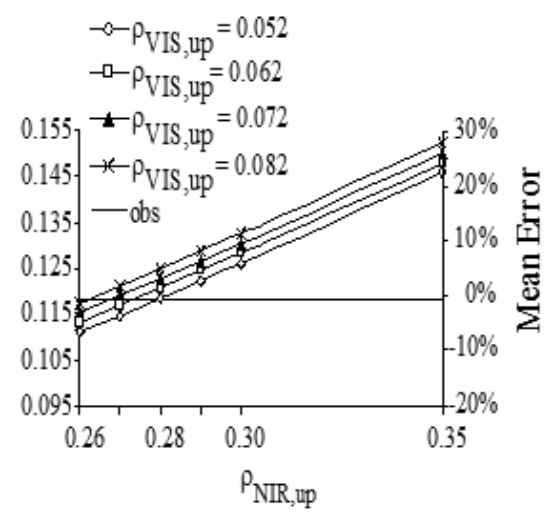

(b) $\gamma_{\text {up }}=0.86$

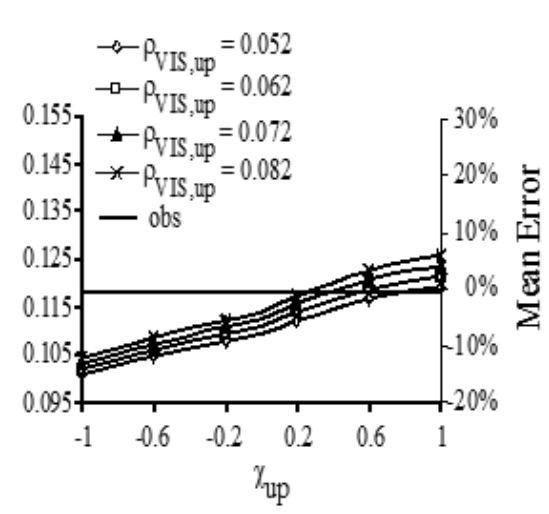

(d) $\rho_{\mathrm{NIR}, \mathrm{up}}=0.28$

Fig. 4 - Sensitivity analysis of the simulated albedo and its mean error as a function of a) $\rho_{N I R, u p}$ and $\chi_{u p}$, b) $\rho_{N I R, u p}$ and $\rho_{V I S, u p}$, setting $\chi_{u p}=0.86$, c) $\chi_{u p}$ and $\rho_{N I R, u p}$, and d) $\chi_{u p}$ and $\rho_{V I S, u p}$, setting $\rho_{N I R, u p}=0.28$, for the Cuieiras Biological Reserve (K34).

Figure 5 shows the temporal variation of the observed and simulated albedos considering different values of the optical parameter $\chi_{u p}$ for five selected days. In these simulations, $\rho_{N I R, u p}=0.275$ and $\rho_{V I S, u p}=0.062$. The model best represents the diurnal cycle with $\chi_{u p}=0.86$.

The sensitivity of the Root Mean Square Error (RMSE) between simulated and observed albedos as a function of the variation of the canopy optical parameters is shown in Figure 6. This analysis indicates that the combination of the canopy optical parameters that minimize the RMSE are $\chi_{u p}=0.86, \rho_{V I S, u p}=0.062$ and $\rho_{\text {NIR, up }}=0.275$, confirming the results obtained in Figures 2 and 3. Again, these parameters are obtained assuming that $\rho_{V I S, l o}=0.062, \rho_{N I R, l o}=0.60$ and $\chi_{l o}=0.10, L=6.175, S=0.025, f_{u p}=0.975$ and $f_{l o}=0.5$. 
The results indicate that the albedo simulated by IBIS is mostly sensitive to the parameters $\chi_{u p}$ and $\rho_{N I R, u p}$. Although Bonan (1996) and Oleson et al. (2004) report that the good fit is obtained for $\chi_{u p}$ in the range -0.4 to 0.6 in this study, the minimization of the mean relative error and the RMSE is achieved for $\chi_{u p}=0.86$. This parameter reduces significantly the effect of the zenith angle on the albedo during sunrise and sunset (Fig. 5). Lower daily amplitudes of surface albedo are expected when the canopy architectural parameter, $\chi_{u p}$, describes the upper canopy elements as mainly horizontally distributed, as shown in Figure 5. For $\chi_{u p}=0.6$, the daily amplitude of the surface albedo is overestimated, while for $\chi_{u p}=1.0$ it has a flat daily profile.

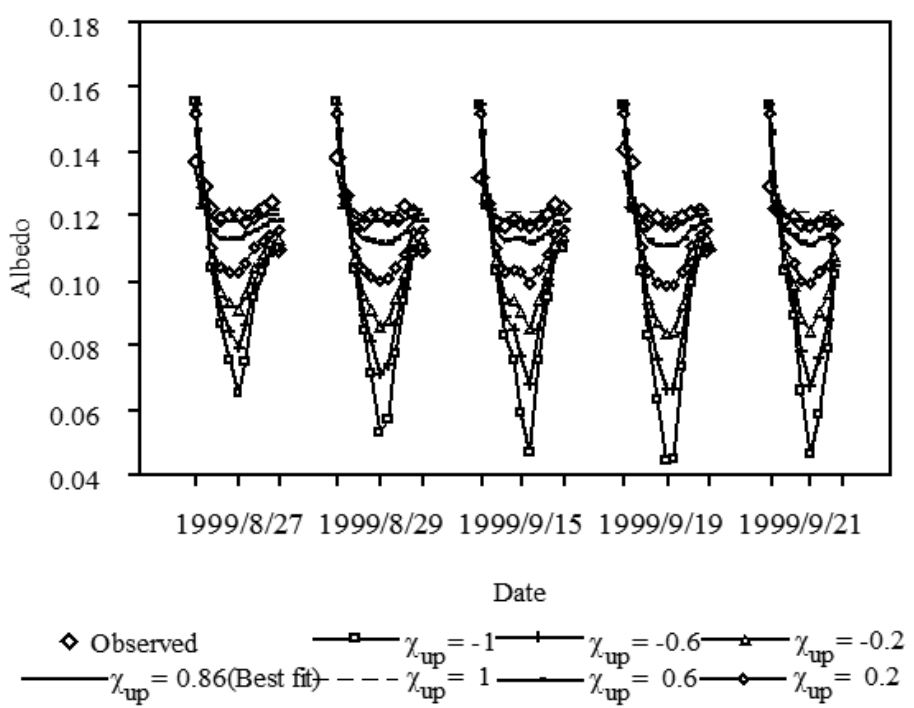

Fig. 5 - Temporal variation of the albedo observed in the Cuieiras Biological Reserve (K34) and the albedo simulated by the IBIS model, according to the upper canopy element orientation parameter.

\section{CONCLUSIONS}

This study evaluates the sensitivity of the surface albedo simulated by IBIS to a set of tropical rainforest canopy architectural and optical parameters. The results are evaluated against albedo measurements taken above the K34 site at the Cuieiras Biological Reserve. Sensitivity analysis indicates a strong response to the parameters $\chi_{u p}$ and $\rho_{N I R, u p}$, a smaller sensitivity to $\rho_{V I S, u p}$ and no sensitivity at all to the lower canopy parameters $\chi_{l o}, \rho_{V I S, l o}$ and $\rho_{N I R, l o}$, which is consistent with the canopy structure. The combination of parameters that minimize the RMSE and mean relative error RMSE are $\chi_{u p}=0.86, \rho_{V I S, u p}=0.062$ and $\rho_{N I R, u p}=0.275$. From the analysis of Figures 2, 3 and 4, however, it seems reasonable to conclude that values of $\chi_{u p}$ in the range of 0.8 to 0.9 , of $\rho_{V I S, u p}$ in the range of 0.05 to 0.07 , and $\rho_{N I R, u p}$ in the range of 0.26 to 0.28 yield results that provide the better values of RMSE, with little variation among them.

The successful simulations of tropical rainforest albedo by IBIS indicate its potential to simulate the canopy radiative transfer for narrow spectral bands and for close comparison with remote sensing products. Additional parameterizations of the canopy architectural and optical parameters according to the plant species, soil types, plant phenology, leaf water content and soil surface wetness may improve considerably the scope of such modeling exercises, building a solid basis for stronger interactions among field observations, climate models and remote sensing products. 


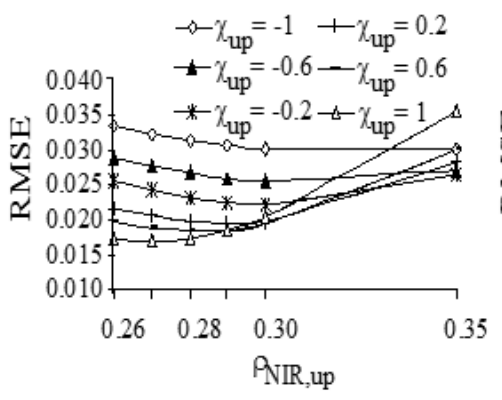

(a)

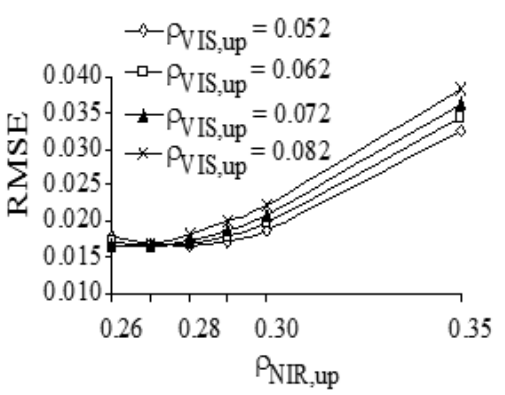

(b) $\chi_{\text {up }}=0.86$

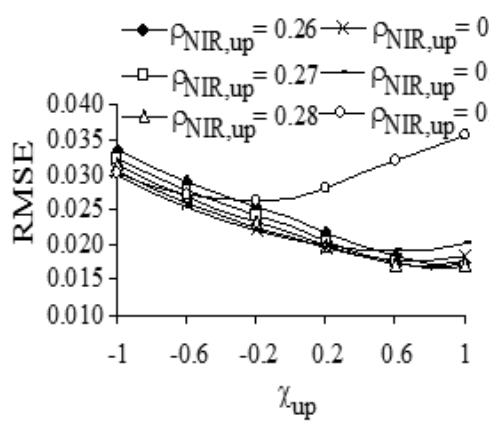

(c)

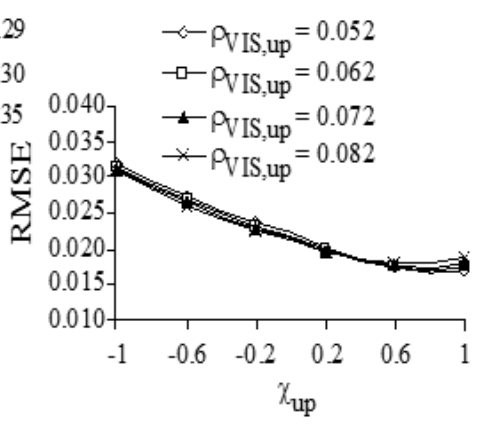

(d) $\rho_{\mathrm{NIR}, \text { up }}=0.28$

Fig. 6-Root Mean Square Error (RMSE) between the observed and simulated albedo as a function of the canopy optical parameters $\rho_{N I R, u p}$ and $\chi_{u p}$, for the Cuieiras Biological Reserve (K34).

\section{ACKNOWLEDGMENTS}

This research was supported by NASA, through the LBA-ECO program, grant NCC5-335. Silvia Yanagi was supported by a Conselho Nacional de Desenvolvimento Científico e Tecnológico (CNPq) fellowship to the graduate program in Agricultural Meteorology, UFV. Data collection at the K34 site has been supported by Projects EUSTACH-LBA and CARBONSINK, funded by the European Commission, grants ENV4CT97-0566 and EVK24-CT1999-00023, respectively. We thank Antônio D. Nobre and Alessandro C. de Araújo for their comments on the manuscript, and Ricardo Dallarosa and Hermes Xavier for helping with the data collection. K34 data are available at http://lba.cptec.inpe.br/beija-flor.

\section{RESUMO}

Este estudo avalia a sensibilidade do albedo da superfície pelo Simulador Integrado da Biosfera (IBIS) a um conjunto de parâmetros que representam algumas propriedades arquitetônicas e óticas do dossel da floresta tropical Amazônica. Os parâmetros testados neste estudo são a orientação e refletância das folhas do dossel superior e inferior nas bandas espectrais do visível (VIS) e infravermelho próximo (NIR). Os resultados são avaliados contra observações feitas no sítio K34 pertencente ao Instituto Nacional de Pesquisas da Amazônia (INPA) na Reserva Biológica de Cuieiras. A análise de sensibilidade indica uma forte resposta aos parâmetros de orientação das folhas do dossel superior $\left(\chi_{u p}\right) \mathrm{e}$ à refletância na banda do infravermelho próximo $\left(\rho_{N I R, u p}\right)$, uma menor sensibilidade à refletância na banda espectral do visível $\left(\rho_{V I S, u p}\right)$ e nenhuma sensibilidade aos parâmetros da parte inferior do dossel, o que é consistente com a estrutura do dossel. A combinação de parâmetros que minimizaram a raiz do erro quadrado médio e o erro relativo 
médio são $\chi_{u p}=0,86, \rho_{V I S, u p}=0,062 \mathrm{e} \rho_{N I R, u p}=0,275$. As parametrizações realizadas resultaram em simulações bem sucedidas do albedo de floresta tropical pelo IBIS, indicando seu potencial para simular a transferência radiativa do dossel para bandas espectrais estreitas, permitindo a comparação com produtos de sensoriamento remoto.

Palavras-chave: Floresta Tropical Amazônica, albedo, transferência radiativa, modelagem.

\section{REFERENCES}

ARAÚJO AC ET AL. 2002. Comparative measurements of carbon dioxide fluxes from two nearby towers in a central Amazonian rainforest: The Manaus LBA Site. J Geophys Res-Atmos 107: 5801-5820.

BONAN GB. 1996. A Land surface model (LSM version 1.0) for ecological, hydrological, and atmospheric studies: technical description and user's guide. NCAR Technical note TN-417+STR, $150 \mathrm{p}$.

COAKLEY JA AND CHYLEK P. 1975. The two-stream approximation in radiative transfer: Including the angle of incident radiation. J Atmc Sci 32: 249-261.

DICKINSON RE. 1983. Land surface processes and climate-surface albedos and energy balance. Adv Geophys 25 : $305-353$.

Dickinson RE, Pinty B And Verstraete MM. 1990. Relating surface albedos in GCMs to remotely sensed data. Agric For Meteorol 32: 109-131.

Foley Ja, Prentice iC, Ramankutty N, Levis S, Pollard D, Sitch S and Haxeltine A. 1996. An integrated biosphere model of land surface processes. Global Biogeochem Cycles 10: 603-628.

KondRATYEV KY. 1972. Radiation processes in the atmosphere, No. 309. Geneva, WMO.

MEADOR WE AND WEAVER WR. 1980. Two-stream approximations to radiative transfer in planetary atmospheres: a unified description of existing methods and a new improvement. J Atm Sci 37: 630-643.

Norman JM And Jarvis PG. 1975. Photosynthesis in Sitka Spruce. V. Radiation penetration theory and a test case. J Appl Ecol 12: 839-878.

Oleson KW ET AL. 2004. Technical description of the Community Land Model (CLM). NCAR Technical note TN-461+STR, $174 \mathrm{p}$.

Pinty B, Lavergne T, Dickinson Re, Widlowski J-L, Gobron N and Verstraete MM. 2006. Simplifying the interaction of land surfaces with radiation for relating remote sensing products to climate models. J Geophys Res 111: 1-20.

Ross J. 1981. The Radiation Regime and Architecture of Plant Stands. Springer, New York, 391 p.

SELLERS PJ. 1985. Canopy reflectance, photosynthesis and transpiration. Int J Remote Sens 6: 1335-1372.

Verstraete MM. 1987. Radiation transfer in plant canopies: Transmission of direct solar radiation and the role of leaf orientation. J Geophys Rev 92: 10985-10995. 